\title{
NOTICIAS SOBRE EL IMPRESOR FELIPE TERUEL MARTÍNEZ
}

\author{
Amparo García Cuadrado* \\ Facultad de Comunicación y Documentación. Universidad de Murcia.
}

\begin{abstract}
Resumen. El artículo lleva a cabo un acercamiento a los primeros años de actividad del impresor aragonés Felipe Teruel en la ciudad de Murcia. El hallazgo de nuevas escrituras públicas, la consulta de fuentes municipales y la propia producción tipográfica han sido los ejes fundamentales de una investigación que pone de manifiesto el rápido ascenso del tipógrafo en la segunda mitad del siglo XVIII, sus relaciones profesionales, y las circunstancias personales que marcarán su actividad como librero e impresor desde de los años cuarenta en Murcia. La exposición de estas informaciones se lleva a cabo dentro del contexto tipográfico del momento, de sus peculiaridades y de la situación de indiferencia hacia el arte impresor por parte de las autoridades del Reino. Se dan a conocer, finalmente, algunos datos sobre las disposiciones testamentarias del impresor y la situación del taller después de su muerte.

Palabras clave: Murcia; imprenta (s. XVIII); librería (s. XVIII); Felipe Teruel; Antonio Roncales; Felipe Díaz Cayuelas; José de los Llanos; José Fandos; imprenta y gobierno municipal.
\end{abstract}

Title: NEWS ABOUT FELIPE TERUEL MARTÍNEZ.

Abstract: The article approaches to the reader to the early years in the activity of the Aragonese printer Felipe Teruel in Murcia. The discovery of new public deeds, enquiries of municipal sources and the typographic production itself, have been the basic axes for a research which shows the printer's quick promotion in the second half of 18th century, his professional relationships, and the personal circumstances that concern his activity as bookseller and printer from the forties in Murcia. The explanation of this information take place in the typographic context of the time, conditioned by the particularities of the situation, defined by the indifference to the art of printing from the authorities of the Kingdom. Finally, the article reveals some data upon the printer's testamentary regulations and the situation of his workshop after his passing.

Keywords: Murcia; printing in the 18th century; bookshop in the 18th century; Felipe Teruel; Antonio Roncales; Felipe Díaz Cayuelas; José de los Llanos; José Fandos; printing and City Government.

\section{INTRODUCCIÓN}

La imprenta murciana de la segunda mitad del siglo XVIII tiene su máximo exponente en el taller de los Teruel. La primacía de esta oficina dentro del panorama tipográfico nos llevó hace un tiempo a analizar el primer período de su producción y las características de la misma a partir de los datos aportados por los propios impresos conservados (García Cuadrado, 2005, 2006, 2008). Hoy nos proponemos alumbrar, mediante otras diversas fuentes de información, algunos aspectos todavía ignorados de la trayectoria vital y del quehacer profesional de Felipe Teruel Martínez (17221780), el fundador de la imprenta de la calle del Pilar que pronto pasaría a la calle Lencería hasta su clausura en la centuria decimonónica. En aquellos días, poníamos en conocimiento de los interesados la diversidad y calidad de los impresos religiosos o de devoción, los festivos y de entretenimiento, los académicos, teológicos, médicos, históricos, legales, etc., que gracias a la buena gestión de este profesional del libro verían la luz durante los más de veinte años en que estuvo al frente de su oficina. Se trataba de una visión de conjunto, una aproximación a las líneas rectoras de su producción ante la falta de un repertorio tipobibliográfico que hubiera permitido dar la medida más exacta de la actividad de aquellas prensas entre 1759 a 1780 , año de la muerte del impresor.

Una vez más, la fructuosa revisión de los protocolos notariales ha proporcionado nuevos documentos con noticias de interés que van a permitir aclarar una etapa todavía ignorada: los inicios de su actividad en Murcia. A estas fuentes hemos sumado otros datos localizados en libros parroquiales, actas y legajos municipales. Todas estas informaciones se complementan con el análisis de algunos impresos que confirman la relación con el tipógrafo y grabador oriolano Alagarda, así como la trayectoria ascendente de Felipe Teruel al poner desde muy pronto sus prensas al servicio de las instituciones administrativas y religiosas. Por último, veremos las disposiciones testamentarias y el devenir de la oficina después de la muerte de su fundador.

Este acercamiento a la figura y actividad de Felipe Teruel nos lleva a exponer noticias sobre impresores y libreros, "gente importante" dentro del ramo, pero también a conocer otros nombres, "gente menuda" de la que hasta el momento no teníamos conocimiento de su existencia, o a penas figuraban en el contexto de la librería e imprenta de la

*ampagar@um.es

Recibido: 12-09-2014; aceptado: 19-11-2014.

GARCÍA CUADRADO, A. Noticias sobre el impresor Felipe Teruel Martínez. Anales de Documentación, 2015, vol. 18, n 1. Disponible en doi: http://dx.doi.org/10.6018/analesdoc.18.1. 206131 
época. Somos de la opinión de que, si prestamos la debida atención a estos nombres menores, podremos dibujar de manera más realista la historia tipográfica y librera del Reino.

\section{PRIMERA NOTICIA: UN SOCIO Y UNA CASA COMPARTIDA}

En abril de 1746 Antonio Roncales y Felipe Teruel acudían al registro notarial con objeto de poner en firme las condiciones de la "asociación” que tenían formada ${ }^{1}$. El primero de ellos, Antonio Roncales Sanz, era un joven maestro de librero que, procedente del Reino de Aragón, se encontraba establecido en la calle del Pilar. Al amparo de otros libreros aragoneses desarrollaba su actividad mercantil desde los años 30 en el barrio de San Pedro, núcleo primigenio de la librería murciana. Roncales, que era natural de Calatorao en Zaragoza, había casado en marzo de 1739 con la murciana María Ramírez ${ }^{2}$, un evento que había contado como testigos con el también maestro librero y mercader aragonés Juan Royo Pérez con tienda en el mismo barrio, frente al convento franciscano (García Cuadrado, 2009, p. 416 y ss.), y con el oficial de impresor Gerónimo Vicen Pérez, feligrés de San Pedro, que probablemente trabajara en la oficina de los Díaz Cayuelas en el Plano de San Francisco ${ }^{3}$.

Trascurridos unos años, el padrón de la parroquial de San Pedro de 1743 da noticia de que el librero, que contaba con 26 años, estaba casado y tenía ya dos hijos varones ${ }^{4}$. Poco después debió de morir su esposa ya que en marzo de 1746 contraía segundas nupcias con Rosa Falcón, natural de Murcia y feligresa de su misma parroquia. Al parecer, Rosa disfrutaba de una posición social y económica interesante pues provenía de una familia bien relacionada y con cierto patrimonio -casa propia, tierras en Carrascoy y en otros pagos-, unos bienes obtenidos con la Venta de la Sal. A diferencia de su anterior enlace, los testigos de este segundo matrimonio no procedían de su entorno socio-profesional sino que fueron elegidos en consonancia con la posición de su nueva familia política: el regidor Rafael Lisón y el notario Cano de Santayana ${ }^{5}$. De esta unión nacería solamente un hijo, Antonio, el único que alcanzó la edad adulta y que acabó ejerciendo la profesión del padre ${ }^{6}$. El caso es que inmediatamente después de aquella boda, el novio formalizaba ante notario la asociación que mantenía con el también aragonés Felipe Teruel.

En efecto, el socio de Roncales era natural de Aguilar, obispado de Teruel; debió de llegar a Murcia en 1744 y fue acogido por el colectivo de aragoneses que ejercían las actividades de compraventa de impresos en la capital del Segura (García Cuadrado, 2009 b) ${ }^{7}$. Sin embargo, al contrario que aquellos, Felipe se dedicaba también al arte impresor, un oficio que, junto a la venta de impresos menores, le permitía sobrevivir en su tierra adoptiva como oficial de alguna imprenta. En febrero de 1745, con 23 años, contraía matrimonio con Antonia Ramírez, hermana de la mujer de Roncales, quien como era de esperar actuó de testigo en la boda de su cuñada ${ }^{8}$. Quedaba así reforzada, a través de lazos familiares, la estrecha relación existente entre ambos profesionales quienes pasaban a residir en la misma vivienda de la calle del Pilar, una casa arrendada por Antonio tiempo atrás.

Esta situación de convivencia entre los dos matrimonios quedaría rota con la prematura muerte de María y el nuevo matrimonio del viudo, causa más que probable de algunas desavenencias y recelos entre los cuñados, un tema delicado que deja traslucir la escritura de concierto firmada un mes más tarde de la llegada de Rosa, la nueva esposa, a la vivienda antes común. Dice así el documento:

En la ciudad de Murcia en veinte y un días del mes de Abril mil setecientos quarenta y seis años, ante mí el escribano y testigos parecieron Felipe Theruel, de ejercicio ympresor, y Antonio Roncales, mercader de libros, vecinos de ella y dixeron que en atención à haver havitado ambos una casa en la población de esta ciudad, calle que nombran del Pilar, que estava a cargo su arrendamiento de Antonio Roncales, quien aviendo tomado estado, de una conformidad para evitar discordias y luchas han determinado unánimes y conformes por interposición de algunas personas, en hacer compañía a pérdida o ganancia, poniendo iguales cantidades para las compras de papel florete, ordinario y de todas marcas maior y menor, como de romances, ystorias, estampas y comedias, en cuio comercio ambos an de poder comerciar y vender en sus casas, llevando para ello libro de cuenta y razón para darla el uno al otro, y el otro al uno, siempre que por cualquiera de los dos se pida, siendo del cargo del dicho Felipe Theruel la compra del referido papel blanco de Valencia ó de las demás partes donde se encontrase, y de la del dicho Antonio Roncales de los demás géneros ympresos que ban expresados; y conducidos dichos géneros, cada uno de los otorgantes a de aportar la mitad de el importe de dichos géneros cuia contrata y comercio a de durar todo el tiempo en que el dicho Theruel avitase en la casa que al presente mora, porque si de ella se mudase el dicho Theruel, desde el mismo día, ha de cesar dicha compañía, siendo condición que el dicho Theruel no a de poder bender libros algunos por sí ni por otra persona; cuia compañía se a de entender únicamente en esta ciudad y si se saliese fuera de ella, a las ferias, a de ser con caudal separado al de la contrata a lo que a ambos se les a de poder apremiar por todo rigor de derecho ${ }^{9}$. 
El texto transcrito, de gran riqueza informativa, deja claro que, ante la nueva situación personal del librero mercader de libros puntualiza la escritura-, el matrimonio Teruel-Ramírez había abandonado la vivienda arrendada por Roncales, y pasado a ocupar otra casa en la misma calle del Pilar. Desde allí, Teruel podía vender en comandita con su cuñado papel de diversas calidades y procedencias que el mismo proveía, así como toda una serie de menudencias literarias -romances, historias, comedias- y las solicitadas estampas piadosas, costeadas por el socio, no así libros impresos, un sector en el que Teruel no podía tener arte ni parte. Además, era condición necesaria permanecer en la casa que habitaba -¿por la proximidad al socio y facilidad de control de sus actividades?- y no poder asistir con aquellos géneros menores a las ferias y mercados fuera de la ciudad, una actividad obligada para cualquier librero si quería colocar su mercancía. La asociación entre los antiguos cuñados debió de funcionar poco tiempo; en septiembre de 1747 el librero y mercader de libros sacaba una copia de la escritura y, aunque no hemos visto nota alguna de cancelación, es probable que cada uno funcionase ya de modo independiente.

Poco más sabemos sobre ambos; en 1751 Antonio Roncales hacía testamento nombrando como albaceas a su madre política y a su mujer. La firma del librero es irreconocible y a duras penas logró terminarla a consecuencia de la gravedad de su estado ${ }^{10}$. Declara que no pudo aportar bienes al matrimonio -a pesar de sus actividades mercantiles-, mientras que su esposa llevó una buena dote: bienes muebles, alhajas y algunas propiedades heredadas de su padre. El fondo de su negocio no se reducía a pequeñas menudencias sino a impresos de mayor entidad. Entre los deudores se encontraban varios religiosos, algunos seglares e incluso un joven colega de profesión, Juan Polo Ruiz, con tienda en el mismo barrio, a los que había proporcionado textos de ortografía, teología, historia y medicina de segunda mano. Y es que Roncales trabajaba con ejemplares procedentes de la compra de librerías. Así, entre las deudas declaradas en su testamento se encuentra "una cierta cantidad del valor" de la librería de D. Alfonso Mesía que todavía debía a sus herederos $^{11}$. Como entendido en el mercado del libro “de viejo" era requerido en la tasación de bibliotecas, una actividad que tenemos documentada en compañía del maestro Royo; se trata de la partición de bienes de un difunto boticario poseedor de una importante librería ${ }^{12}$. Su cuñado Francisco Falcón, que era agrimensor público y se ocupaba del arriendo de las tierras de la familia, trabajaba ocasionalmente como intermediario del librero proporcionándole alguna clientela y actuando como su fiador. En cuanto a su mujer, no parece que colaborase en el negocio de impresos. Rosa estaba dedicada a su madre viuda, Melchora de los Reyes, e incluso llevaba la Venta de la Sal que aquella tenía a su cargo; por todos estos desvelos sería mejorada por su progenitora frente a sus hermanos con una casa, la vivienda familiar del barrio de San Pedro ${ }^{13}$.

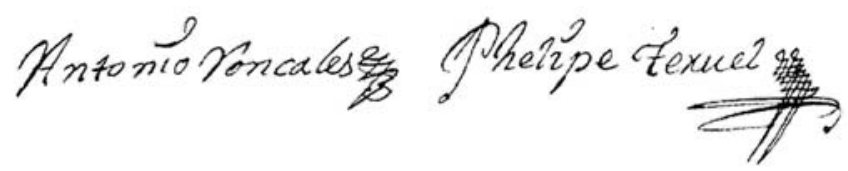

Figura 1. Firmas de Roncales y Teruel. Fuente: “Antonio Roncales, mercader de libros, y Felipe Teruel, ympresor, vecinos desta ciudad, escriptura de convenio”. (A. H. P. Murcia).

Por su parte, Felipe conseguía salir adelante con el ejercicio de oficial de imprenta más la venta de papel y pequeños impresos, actividad comercial probablemente en manos de su esposa o con la ayuda inestimable de ella. Muchos años más tarde, el testamento de la pareja informa de manera rotunda sobre la participación activa de ambos en el aumento de sus caudales ${ }^{14}$. A decir verdad Teruel mantendrá una posición dual en su situación profesional, al menos hasta que su faceta de impresor quedara perfectamente consolidada. En 1755, poco antes de abrir taller, declaraba ante notario ser maestro de librero con el mismo rango que otros conocidos libreros de la ciudad -Juan Royo, Juan Polo, Gregorio Gómez, Francisco de Gea y Francisco Benedicto-, sin hacer alusión alguna a su condición de impresor ${ }^{15}$.

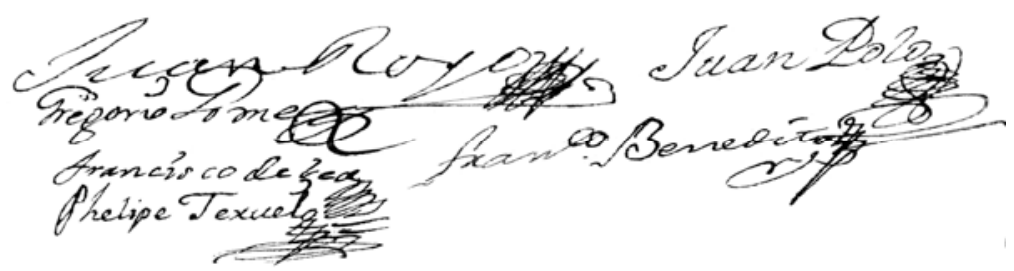

Figura 2. Firmas de libreros. Fuente: “Los Maestros de Libreros de esta Ciudad, poder general a Joseph Fernández de Rueda”. (A. H. P. Murcia). 


\section{SEGUNDA NOTICIA: UN IMPRESOR SIN IMPRENTA}

Hemos leído en la escritura de concierto que Felipe ejercía como impresor, pero nada se especifica acerca de su rango dentro de la profesión. En 1756 las respuestas del Catastro de Ensenada afirman que Teruel desempeñaba como oficial de imprenta, un grado inferior al de maestro, pero con el oficio suficiente para trabajar al frente de un taller tipográfico (Lemeunier, p. 168). En esa época solo disponía la ciudad de Murcia de tres imprentas; además de la ubicada en el Convento de S. Francisco (1753-1766), funcionaban la de Felipe Díaz Cayuelas (1738-1774) frente al convento franciscano, y la de Nicolás Villargordo y Alcaraz (1746-1761) instalada en aquellos días en la Plazuela de S. Juan de Dios. Tanto Díaz Cayuelas (49 años) como Villargordo (40 años), en tanto que maestros en el arte impresor, obtenían al año 2.160 reales; el resto de los nombres recogidos en la fuente catastral eran simples oficiales y por su trabajo percibían 720 reales anuales. Esta última era la situación de Antonio Morenete Villarrasa, de 70 años y con un hijo oficial, la de José de los Llanos, oficial de 50 años, la de José Fandos de 27 años y la de Juan Marín de 30, todos ellos casados (García Cuadrado, 2011) ${ }^{16}$. Más abultada era la economía de Felipe Teruel (34 años) pues, aunque como oficial percibía los 720 reales estipulados para su categoría profesional, la venta de papel incrementaba sus haberes al ingresar por dicha actividad hasta 1.100 reales, un producto que vendía a las imprentas y a las librarías de su entorno; al menos es lo que sugiere la documentada deuda que el librero Polo Burillo dejó pendiente tras fallecer en 1749 (García Cuadrado, 2009 b, p. 19) ${ }^{17}$.

Deberíamos preguntarnos si la situación de asalariados de los oficiales de imprenta citados fue una constante a lo largo de su vida profesional. Según los escasos vestigios localizados podemos afirmar que José de los Llanos y José Fandos habían dispuesto de imprenta propia en algún momento. Sobre el primero se sabe que en julio de 1754 el Ayuntamiento ordenaba se le pagasen 24 reales por la impresión de una tirada de 200 edictos acerca de la normativa de construcción de barracas en la huerta ${ }^{18}$.

Es esta una noticia que merece alguna puntualización. Dado que se trataba de un encargo del Ayuntamiento, resulta extraño que los munícipes recurriesen a Llanos, un impresor cuya actividad debía de ser limitadísima pues nada ha quedado de su producción; es muy probable que contase con una pequeña prensa para impresiones de papeles, menudencias y esquelas, unos impresos que raramente se conservan en el tiempo. En aquella época, el impresor de la Ciudad, con nombramiento oficial, era Díaz Cayuelas y su relación con la misma no atravesaba por sus mejores momentos, al punto de haber presentado un Memorial de queja a los munícipes. El Acta Capitular de 9 de noviembre de 1754 informa sobre ello:

Libranza al Impresor. El presente secretario Don Pedro Faxardo dijo: que de acuerdo con don Juan Hortador, Mayordomo de Propios, à reconocido el Memorial presentado por Phelipe Diaz Cayuela, impresor de este Ayuntamiento, en que haze relación y pide nuevezientos setenta y dos reales vellón de las impresiones que tiene hechas de varias reales órdenes, pragmáticas, pasaportes, aranceles de caballeros fieles executores, y otros muchos impresos de diferentes asumptos que pertenecen al servicio de ambas Magestades y venefizio común de esta población, desde el año pasado mil setezientos cuarenta y seis, y menudamente regateando con dicho impresor cada una de las catorze impresiones que tiene valuadas en dicha cantidad de las que han hecho las revajas que les à parecido justas según su sentir, práctica y conocimiento dexando reduzidos dichos nuevecientos y setenta y dos reales con convenio del referido impresor à quinientos y noventa que se le deverán satisfacer: sobre que la Ciudad resolverá lo que fuere de su agrado. Y haviéndolo visto acordó se despache libramiento de los expresados quinientos y noventa reales a favor del nombrado Phelipe Díaz Cayuelas contra los efectos de Propios y su Administrador don José López Belmonte ${ }^{19}$.

La lectura del texto pone en evidencia que los impagos era una constante preocupación -como lo sigue siendo hoypara quienes suministraban servicios a la Administración. Según el afectado, eran ya 8 años los que llevaba sufriendo aquellas demoras, una situación que, sin embargo, no conseguía desalentar a los impresores, siempre dispuestos a conseguir para sí un título oficial. Naturalmente, tal nombramiento debía constituir más bien una vía para fomentar las relaciones con las clases pudientes y letradas de la ciudad, y un signo de prestigio dentro del sector, que el logro efectivo de buenos dividendos (Burgos y Peña, p. 196) ${ }^{20}$. Solo de vez en cuando surgía algún encargo más lucrativo y lustroso que los meros papeles oficiales o simples pliegos sueltos, una cuestión sobre la que luego insistiremos ${ }^{21}$. Pues bien, ese encargo realizado a José de los Llanos en lugar de a Cayuelas por el Ayuntamiento pudo ser un hecho aislado, precisamente motivado por el hastío del "impresor oficial", el escaso lucimiento del impreso y su poca ganancia, razones de peso para ceder sus derechos a quien posiblemente trabajase o lo había hecho en su imprenta como oficial. Decimos esto porque J. de los Llanos, que era natural de Ocaña (Toledo), viudo y casado en segundas nupcias con una murciana, había celebrado su segundo matrimonio en la parroquia de San Antolín, iglesia de la que eran feligreses; precisamente, en aquel barrio se encontraba la imprenta de Felipe Díaz Cayuelas, quien acudió a la 
ceremonia en calidad de testigo, un hecho que denota el grado de relación personal y/o profesional con los contrayentes $^{22}$.

En cuanto a José Fandos Ximeno hemos visto tres impresos salidos de su propia oficina sita "enfrente de San Lorenzo" a finales de la década de los años cuarenta ${ }^{23}$. Se trataba de un taller perfectamente equipado para poder afrontar la impresión de textos de cierta envergadura, y en donde se hacía uso de algunos adornos empleados en el ya clausurado de los Mesnier (García Soriano, p. 626-627) ${ }^{24}$. El cotejo de tres elementos decorativos (iniciales y remate), estampados por Fandos en la Oración fúnebre en memoria de Felipe V, nos remite a las cajas de la imprenta Mesnier cuya última ubicación en la ciudad se encontraba precisamente en el barrio de San Lorenzo (junto a Santa Quiteria). Ambos datos, localización y reutilización de xilografías, nos lleva a sospechar que Llanos hubiera adquirido el antiguo taller donde años atrás habría trabajado como oficial.

Es evidente que la situación de independencia de ambos impresores debió durar muy poco; más pronto que tarde aquellos negocios tipográficos se vieron obligados a cerrar sus puertas ante la falta de encargos y sus dueños a ejercer de nuevo como asalariados. También es claro que la clausura de este tipo de talleres no era excepcional dada la tradicional atonía de la imprenta murciana. A este respecto es interesante constatar la situación de angustia e incertidumbre de quien se atrevía a mantener abierta su propia empresa. En mayo de 1759 Bernardo de Roxas Contreras, subdelegado de imprentas, escribía al estricto juez Juan Curiel solicitando autorización para seguir publicando el Semanero de Murcia, un periódico de escaso recorrido -solo había salido tres semanas- ideado por el impresor Nicolás Villargordo (Reyes, p. 70). Antonio de los Reyes, citando a Aguilar Piñal (p. 45), transcribe unos párrafos de gran interés sobre lo que venimos diciendo. Dice así el escrito conservado en el Archivo Histórico Nacional de Madrid: “... cabe dezir a Vds. que con el motivo del diario que salió en esa Corte, y llevado Nicolás Villargordo impresor, del celo de dar aquí algunas noticias útiles al público a imitación de dichos diarios, acudió a mí como subdelegado de Vds. a pedir la lizencia necesaria, la que le concedí (...) habiendo tenido este asunto por los de corta entidad como Vd. me tiene insinuado se puedan y deban permitir para fomento y manutención de estas imprentas que hay en esta Ciudad, por de lo contrario es imposible su subsistencia”. Qué duda cabe que la precariedad del arte impresor en Murcia era bien conocida por el subdelegado; es más, en opinión de A. de los Reyes "la publicación del Semanero tenía por una de sus finalidades básicas la supervivencia del impresor”; dos años más tarde, el murciano Villargordo y Alcaraz marchaba de nuevo a Salamanca donde había trabajado antes de hacerlo en su tierra natal (Reyes, p. 72). Si esta era la situación de los profesionales del sector, nada debe extrañarnos la tardanza en abrir taller por parte de Felipe Teruel a pesar de encontrarse algo más “capitalizado” que los demás oficiales; y aún resulta más sorprendente que, finalmente, lo hiciera cuando la crisis era tan manifiesta como hemos visto.

\section{TERCERA NOTICIA: UN PRIVILEGIO DE IMPRESIÓN}

Es complicado poder establecer con exactitud la fecha de apertura del taller de Teruel, pero creemos que en 1758 contaba ya con su propia oficina. En ese año solicitaba formalmente a los libreros de San Gerónimo la cesión del privilegio de impresión del Catón Christiano, y para ello otorgaba poderes a Bernardo Ortiz, vecino de Madrid. Pese a que nada indica la fuente notarial, podemos asegurar que el tal Ortiz no era otro que el fundidor de letras y proveedor de los tipos de imprenta usados por el tipógrafo oficial de la Biblioteca Real, Antonio Pérez de Soto (Moll, p. 14 y 20 ). El obrador de Ortiz era uno de los más prestigiosos de la Corte (Ponz, p. 147) y no sería descartable que a él hubiese recurrido el propio Teruel a la hora de equipar su taller; de ahí los lazos de confianza establecidos con el fundidor a que alude la escritura ${ }^{25}$ :

En la ziudad de Murzia en siete de junio de mil setezientos zinquenta y ocho años, ante mí el escribano y testigos parezió Phelipe Teruel vezino e impresor de esta ziudad y dijo que por quanto por el Real y Supremo Consejo de Castilla está cedido a la Hermandad del Señor San Gerónimo en la Villa y Corte de Madrid el privilegio de la impresión del Catón Christiano por cierto tiempo y precio, y tener tratado dicha Hermandad con el otorgante el zederle por el tiempo que le queda el zitado privilegio; por no poder por sí el otorgante pasar a dicha Villa y Corte a aceptar la dicha zesión, y hazer la obligación correspondiente por diferentes motivos que le imposivilitan; y teniendo como tiene plena satisfazión de D. Bernardo Ortiz, vezino de dicha Villa y Corte de Madrid, desde luego para que tenga efecto lo relacionado en la mejor forma que puedo, otorga que da todo su poder cumplido (...) para que en su nombre y con representación de su misma persona, acción y derecho, pueda hazer la azeptación de la zesión, que la dicha Hermandad de Señor San Gerónimo de dicha Villa y Corte ha de hazer a este otorgante por el tiempo que a dicha Hermandad le queda del referido privilegio del Catón Christiano.... 
En efecto, conseguir un privilegio de esta naturaleza exigía alcanzar los oportunos acuerdos con los libreros de San Gerónimo, los poseedores tradicionales de los privilegios de impresión y venta de los denominados "libros del Santo", cuatro títulos bien conocidos y de fuerte demanda en el mercado: el Catón cristiano del jesuita Jerónimo Rosales, los Exercicios devotos en que se pide a la Virgen su amparo para la ora de la muerte del obispo Palafox, el Espejo de Cristal fino de Pedro Espinosa y, por último, Oraciones y ejercicios de fray Luis de Granada. Esto significaba que los madrileños tenían monopolizado el negocio de los pequeños impresos doctrinales tan necesarios no solo para las devociones más comunes, sino también para atender las necesidades educativas y de aprendizaje de las primeras letras (Viñao Frago, p. 177-183). Así pues, Teruel esperaba conseguir la impresión en exclusiva para el Reino de Murcia de uno de aquellos libritos, el imprescindible Catón, un tipo de cesión habitualmente practicada por la Hermandad madrileña y que había sido utilizada por los libreros murcianos desde antiguo (Paredes Alonso, p. 33-35; García Cuadrado, 2009 c, p. 36-45).

Por consiguiente, es muy probable que desde 1758 ya estuviera en funcionamiento el taller de Felipe Teruel, aunque la búsqueda sistemática de los primeros productos salidos de aquellas prensas solo nos haya proporcionado dos impresos de 1759. Por un lado, una novena a la Virgen del Populo costeada por los mayordomos de la venerada imagen, el boticario Juan Toribio y el preceptor de gramática latina Juan Asensio. Se trataba de una novena anual -es de suponer que también de un encargo anual- de la que conocemos dos ediciones de Teruel, la ya citada, más otra de 1763 en formato $8^{\circ}$ y una en $16^{\circ}$, sin año, estampada por Díaz Cayuelas ${ }^{26}$. Por otro lado, tenemos un impreso a dos tintas, en formato folio, de índole litúrgica para la diócesis de Orihuela, el primer vestigio de una larga colaboración entre los Teruel y el obispado oriolano, particularmente intensa durante el gobierno de D. José Tormo (1767-1790) ${ }^{27}$.

Estos impresos de materia religiosa constituían tan solo una parte de la producción, ya que siempre se realizaron menudencias literarias y estampas, unos productos editoriales que como ya vimos acostumbraba a despachar desde su asociación con Roncales. El testamento de Antonia Ramírez confirma la constante tirada de "estampas, catecismos y otros papeles” que se imprimían para venderlos en el mismo establecimiento ${ }^{28}$. Hay que considerar también que no todos los impresos conservados incluyen en su pie de imprenta, o en el colofón cuando lo tienen, la fecha de su edición por lo que solo podemos contar con testimonios parciales de la producción de aquellos primeros años.

\section{CUARTA NOTICIA: UN TALLER RELACIONADO CON LA CIUDAD DE ORIHUELA}

En 1760 los encargos al impresor fueron también escasos, pero de venta segura. En ese año da a luz la Preparación de la Missa del asceta y en otro tiempo cuestionado mercedario Juan Falconi ${ }^{29}$, más dos impresos relacionados con la familia real. En el primero, La lealtad testimoniada por el Cuerpo de Escribanos y Procuradores de la Ciudad en la exaltación al trono de Carlos III $^{30}$, Teruel se empleará a fondo en la impresión de la oración que por encargo del citado Cuerpo había compuesto el lector de teología de la Orden de Predicadores, fray José Antonio Funes. Escudo real, viñetas e iniciales xilográficas varias ilustran este trabajo laudatorio cuya estética impresora cargada de barroquismo recuerda tanto a épocas pasadas (Figura 3).
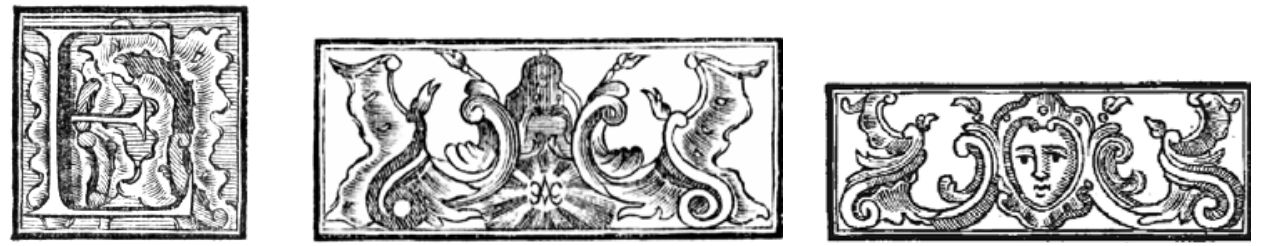

Figura 3. Inicial y viñetas xilográficas. Fuente: La lealtad testimoniada, por el distinguido numero de Escribanos, y Procuradores. Murcia, 1760. (B. A. Municipal de Murcia).

Mucho más abultado es el tercer trabajo fechado ese mismo año de 1760, las Instrucciones ascéticas a Theophila, una suerte de "manual de ascética” dedicado a las Infantas de España por el mercedario Diego Tello Lasso de la Vega, un interesante cliente y que algo debió de contribuir en el ascenso del taller con el otorgamiento de nombramientos oficiales $^{31}$. Fray Diego era consultor de la Sagrada Congregación del Índice y calificador del Santo Oficio Romano. En este impreso el barroquismo de los innumerables adornos utilizados será exultante; hemos computado hasta ocho iniciales xilográficas de gran formato en su mayoría, adornos tipográficos y más de una docena de viñetas xilográficas utilizadas como remates que no pueden por menos de desconcertar al lector moderno. Un verdadero alarde del equipamiento con que podía contar aquella nueva oficina cuyas puertas abrían a la calle del Pilar, la misma en la que en otro tiempo había comenzado a trajinar con su negocio papelero. 
Al año siguiente, el antiguo oficial había conseguido obtener para sí el nombramiento de "Impresor del Santo Oficio de la Inquisición”32(Figura 4), al mismo tiempo que era utilizado también por su tocayo Díaz Cayuela, quien lucía en sus portadas el título desde tiempo inmemorial. Tal vez por ello, Teruel gestionaría con rapidez el más novedoso de "Impressor del Ilmo. Cabildo de la Santa Iglesia de Cartagena" (1762) ${ }^{33}$. Y muy pronto, otro más que original nombramiento que vemos estampado en el pie de imprenta de unos Villancicos para la Navidad de 1764 con destino a la Iglesia Parroquial de Caravaca; reza así: “Impressor de las Reales Fábricas de la Polvora”³4. Se trataba de un título insólito para Murcia pues desde la constitución por la Real Hacienda de las Reales Fábricas de la Pólvora de Murcia en 1747 -molinos de La Nora y el Javalí Viejo- ningún impresor, que sepamos, había disfrutado de uno similar. No sería extraño que tal "honor" estuviese en relación con el comercio papelero del impresor. La continua necesidad de papel de estraza que requerían las fábricas para el empapelo de la pólvora bien pudiera haber sido suministrado por Teruel, del mismo modo que a finales de la centuria lo haría el librero Polo Ruiz como gestor del molino de papel de estraza ubicado en la diputación de Javalí Viejo (García Cuadrado, 2010, p. 32-40).

\section{Impreffa en Murcia , con las licencias necetia- rias, en la Imprenta de Phelipe Teruel , Impref- for del Santo Oficio, vive en la calle dcl Pilar.}

Figura 4. Pie de imprenta. Fuente: Breve noticia de la vida, y virtudes de la Madre Sor Juana Jacinta Romera. Murcia, 1761. (B. Archivo Municipal de Murcia).

Casi un nombramiento por año era ciertamente un buen ritmo para un taller de reciente apertura, y dentro de un contexto local difícil por lo que era obligado buscar clientes en el exterior. Orihuela constituirá para Teruel, como lo había sido tradicionalmente para otros impresores, una vía de escape y promoción que vemos tantear desde los comienzos de su actividad como maestro independiente y, posiblemente, ya antes.

Existen dos hechos que indican las estrechas relaciones del aragonés con la capital de la Vega Baja. En primer término, la utilización de los mismos tacos xilográficos por parte del impresor oriolano José Vicente Alagarda y de Felipe Teruel en impresos salidos de ambas oficinas casi de manera simultánea ${ }^{35}$. El ejemplo más significativo se encuentra en las ya mencionadas Instrucciones asceticas a Theophila (1760) de Tello Lasso de la Vega, quien al año siguiente daría a las prensas oriolanas de Alagarda sus Luces theologicas a Theophila. Pues bien, en ambos impresos la estética impresora es idéntica: portada a dos tintas y profusión de elementos decorativos, seis de ellos comunes (Figura 5).
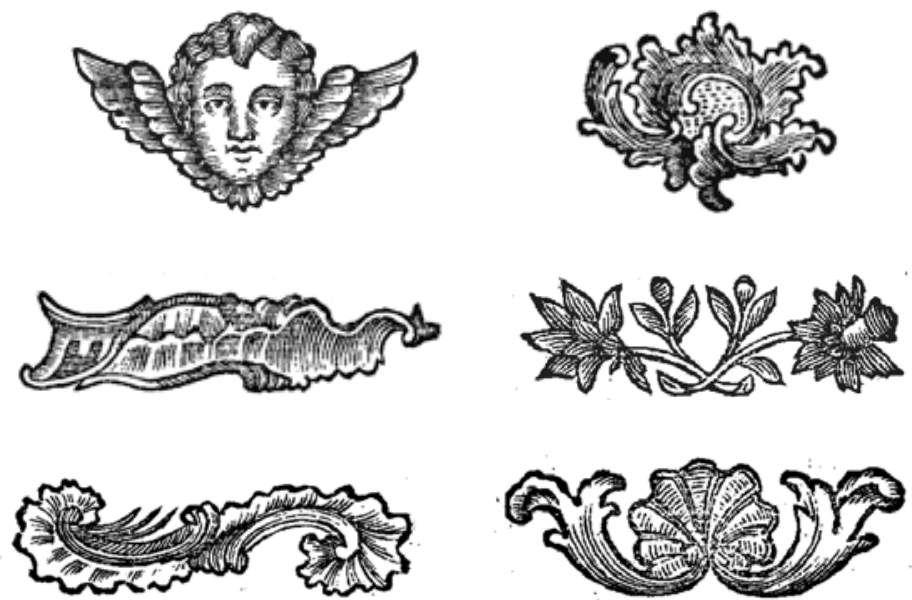

Figura 5. Viñetas xilográficas coincidentes en Instrucciones asceticas a Theophila (Teruel 1760) y Luces theologicas a Theophila (Alagarda 1761). 

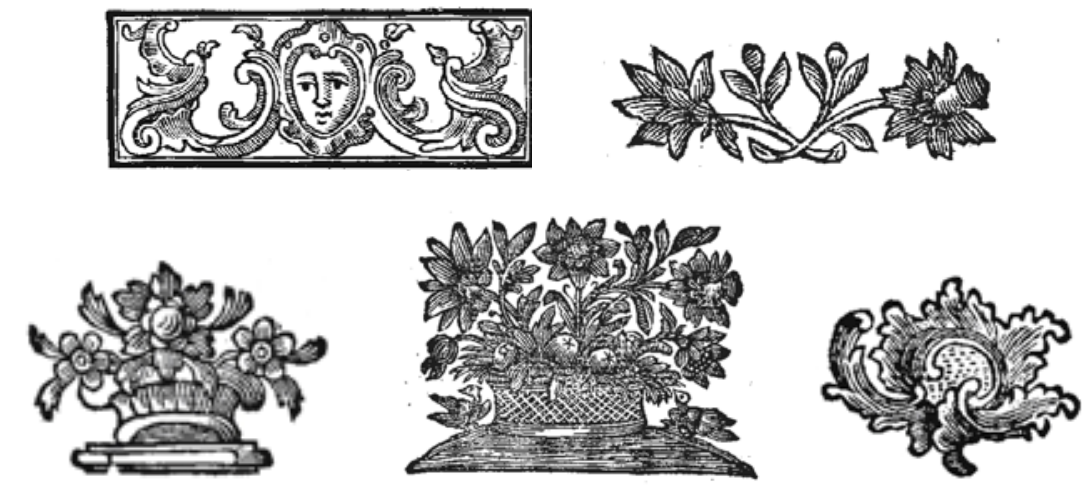

Figura 6. Viñetas xilográficas coincidentes en Instrucciones asceticas a Theophila (Teruel 1760) y Disertacion physico-medica (Alagarda 1760).

Ahora bien, esa no sería la única vez que las prensas de la calle del Pilar harían uso de viñetas utilizadas también por la imprenta de Alagarda en Orihuela. Así, la Disertacion physico-medica estampada por el oriolano en 1760 contiene una muestra de elementos xilográficos, cinco de los cuales engalanan también las Instrucciones asceticas a Theophila (Teruel, 1760) (Figura 6). Y lo mismo podemos decir en cuanto a la existencia de dos coincidencias xilográficas entre la Disertación del Dr. Cerdán (Alagarda 1760) y La Lealtad testimoniada (Teruel 1760) (Figura7).
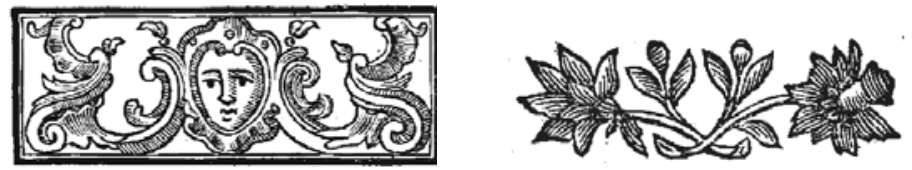

Figura 7. Viñetas xilográficas coincidentes en La lealtad testimoniada (Teruel 1760) y Disertacion physico-medica (Alagarda 1760).

No estamos hablando de viñetas xilografías que se imitan, un hecho bastante frecuente entre impresores, sino de las mismas piezas decorativas sin lugar a dudas y, por consiguiente, de la efectiva existencia de una relación sumamente estrecha y también prolongada entre ambos talleres con el intercambio incluso de algunas iniciales y viñetas en épocas más avanzadas (Figuras 8 y 9).
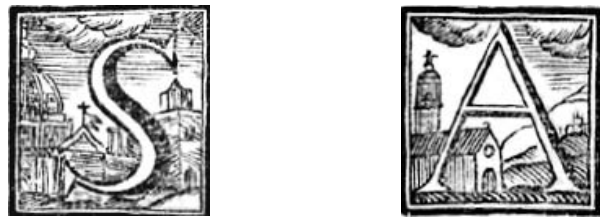

Figura 8. Iniciales estampadas en Luces theologicas a Theophila (Alagarda 1761), Conclusiones philosophicae (Teruel 1768) y Breve Confirmatorio (Teruel 1777).

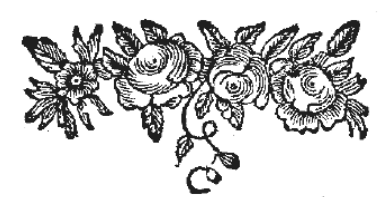

Figura 9. Viñeta utilizada en 1779 por Teruel en unas Conclusiones theologicae y por Alagarda en el Sermon del Beato Miguel Argemir (1779).

Pero, ¿a quién pertenecía aquel “ajuar” tipográfico? No podemos saberlo con seguridad; algunas viñetas seguirían siendo utilizadas por Teruel a lo largo de los años. Otra pregunta que no es posible contestar por ahora es, sin embargo, obligada: ¿Trabajó Teruel como oficial en casa de Alagarda antes de abrir su taller en Murcia? Y por último, ¿quién había diseñado y labrado aquella colección de viñetas e incluso una inicial, también en madera, estampada por Teruel en uno de los impresos citados y que imita los antiestéticos alfabetos floridos empleados por el oriolano? Somos de la opinión de que el artista encargado de componer todo aquel instrumental xilográfico no era otro que el 
propio José Vicente Alagarda e Eisarch (1710-1790), cuyos conocimientos como grabador en madera y metal tenemos perfectamente documentados. En casi todas sus composiciones -de escaso nivel artístico por lo general- hace acto de presencia un barroco recurso compositivo “tipo rocalla” cuyo trazo resulta inconfundible, y que el artista aplicará de manera sistemática en las xilografías y planchas calcográficas salidas de su buril.

Un segundo asunto que debemos considerar es el servicio prestado por Teruel a la diócesis de Orihuela. En algún momento que no podemos precisar lograría para sí el nombramiento de "Impresor del Ilmo. Señor Obispo de Orihuela” aunque no antes de la década de los años 70 (Figura 10). Durante años el Obispo Tormo confiaría al impresor una amplia variedad de documentos oficiales para el gobierno de su diócesis ${ }^{36}$.

\title{
EN MADRID:
}

\author{
En la Imprenté de Pedro Marin ; y por su original, en Murcia, \\ por Felipe Teruel, Impresor del Illmo. Seńor Obispo de \\ Orihuela : Vive en la Lencerì.
}

Figura 10. Pie de imprenta. Fuente: Real Cédula (...) para que los Religiosos no vivan fuera de Clausura. Murcia, 1772. (B. Valenciana Digital).

\section{QUINTA NOTICIA: UN IMPRESOR CON “TITULITIS”}

Los tanteos con las autoridades civiles y religiosas estaban dando ciertamente sus frutos; a los ya citados titulillos se sumaría el de "Impresor del Departamento de Marina de Cartagena”, un empleo que años después ostentarían otros conocidos tipógrafos, pero que sería inaugurado por el aragonés ${ }^{37}$. El de “Impresor de la Dignidad Episcopal” es otro de los cargos que podemos leer en algunos pies de imprenta, incluso antes de la llegada de obispo Rubín de Celis (1773-1784) y, finalmente, el de "Impresor de la Ciudad”, nombramiento que disputará, como el anterior, a Felipe Díaz Cayuelas, el impresor que había acumulado la totalidad de los títulos tradicionales de la imprenta murciana durante varias décadas ${ }^{38}$ (Figura 11).

\section{En Murcia , en la Imprenta de Phelipe Diaz Cayuelas,y Aguado, Impreffor de la Ciudad, y del Santo Oficio de la Inquificion, y del Iluftrifsimo Señor Don Diego de Roxas, Plaza de San Francifco.}

Figura 11. Pie de imprenta. Fuente: Oración fúnebre que en la exequias (...) Da Maria Amalia de Saxonia (...) Reyna de España. Murcia, 1760. (B. Archivo Municipal de Murcia).

Por lo que al de “Impresor de la Ciudad” se refiere, Díaz Cayuela lo había conseguido retener para sí tras morir su tío y mentor José Díaz en 1738, un nombramiento al que también aspiraba Juan Martínez, el maestro de taller de la casa Mesnier. Nuevamente las Actas Municipales constituyen la vía segura para conocer el interés de estos profesionales por poner sus prensas al servicio de las elites rectoras de la Ciudad. Efectivamente, en agosto de 1738 Díaz Cayuelas pedía al Concejo, mediante un memorial, que se le nombrase como impresor menestral; veinte días más tarde, el Ayuntamiento otorgaba al impresor lo solicitado ${ }^{39}$, y en noviembre respondía negativamente a la misma petición realizada por Martínez Mesnier ${ }^{40}$. Conviene señalar que, en su origen, el nombramiento reportaba para el impresor elegido una serie de exenciones concejiles y el disfrute de una casa del Ayuntamiento donde instalar el negocio. Sin embargo, estas prebendas acabarían reducidas a la eliminación de alguna carga tributaria por lo que la situación de privilegio era más aparente que real. Y frente a ello, los impagos y la falta de encargos de envergadura por parte de la Ciudad para con su impresor. Pero veamos dos ejemplos del desinterés que el Concejo de Murcia manifestaba hacia el "Impresor de la Ciudad” y hacia el colectivo del arte impresor en general.

Unos días antes de ser confirmado como impresor menestral Díaz Cayuelas, los munícipes respondían afirmativamente a la petición de una ayuda de costas hecha por el padre Guardián de la Comunidad franciscana de 
Santa Catalina del Monte; la solicitud tenía por objeto realizar la impresión de la vida del religioso lego recoleto fray Martín de Armenta escrita por el también franciscano José Tomás Blanco. La tirada de 500 ejemplares exigía un desembolso de "trescientos ducados de vellón", pero puesto que se contaba con la ayuda del Cabildo Eclesiástico, la Ciudad tan solo tendría que contribuir con la mitad de los ducados presupuestados ${ }^{41}$. Tras la consulta preceptiva, se acordó librar 150 ducados pues el librito en cuestión se hallaba ya “a la zensura de hombres doctos” y contaba con "la dedicatoria â este Ayuntamiento y al Cabildo Eclesiástico (...) y reflexionando lo que en semejantes casos a practicado esta Ziudad, acordó se librasen” ${ }^{\text {„4 }}$. En abril, con la tinta aún fresca, el padre Guardián y la Comunidad franciscana daban "las más expresibas gracias por la limosna que se sirvió franquear para la impresión de la Vida del Venerable Fr. Martín de Armenta, cuya primera encuadernación a repartido [el Concejo] entre los señores Justicia y Cavalleros Capitulares que componen este consistorio" ${ }^{\text {" }}$.

Así pues, en primavera los munícipes tenían en su poder los ejemplares, pero para nuestra sorpresa no fue Cayuelas -el tipógrafo oficial recientemente nombrado- quien había dado a luz la vida de tan meritorio lego, ni siquiera otro impresor de la ciudad fue el encargado de asumir aquel encargo. La tirada fue realiza en Valencia, en casa de Antonio Valle; allí fueron a parar los dineros librados por ambos cabildos, el eclesiástico y el secular, sin que nadie pusiese el más mínimo impedimento ${ }^{44}$. Desde nuestro punto de vista, se trataba de una actitud incomprensible ante la siempre crítica situación de las prensas murcianas que, desde luego, no constituía motivo de preocupación para sus autoridades, ni civiles ni religiosas.

Un segundo ejemplo lo encontramos en octubre de 1747; en ese año tampoco parece que el Ayuntamiento tuviera demasiada consideración con su impresor. Tras la celebración de las fiestas de canonización de los capuchinos san Fidel Sigmaringa y san José de Leonisa, pagadas generosamente por la Ciudad, tocaba llevar a cabo la impresión de los sermones y oraciones compuestas por los oradores más solicitados y dejar constancia en letras de molde de aquellas jornadas tan memorables. El Acta Capitular correspondiente da cuenta del acuerdo de impresión del sermón predicado por el jesuita Joaquín Navarro, un trabajo que fue encargado por los regidores al impresor Nicolás Villargordo ${ }^{45}$; a este mismo tipógrafo el Cabildo Eclesiástico encomendó el sermón pronunciado por el también jesuita Pedro Tomás Torrubia ${ }^{46}$, e incluso tiró en sus prensas el Sermón panegyrico predicado por el capuchino García Benito el tercer día de la octava de canonización ${ }^{47}$. Y aunque la Ciudad había olvidado a su impresor, Díaz Cayuelas pudo sacar algunos reales de aquellas jornadas imprimiendo en diciembre, a costa de un devoto de los santos, una Oración panegyrica $^{48}$; y poco antes, también a costa de otro devoto, la Vida de San Fidel de Symaringa, un impreso de mayor envergadura y con presencia de grabado calcográfico ${ }^{49}$.

Pues bien, esta situación de permanente desafecto hacia el impresor oficial bien pudo incrementar los deseos de Teruel por hacerse con todos los títulos en manos de su opositor. Transcurridos bastantes años, y aprovechando los graves problemas económicos que arrastraba Cayuelas y la decadencia de su negocio, el aragonés presentaba a finales de 1771 la correspondiente petición al Ayuntamiento:

“Teniendo presente la Ciudad la súplica que haze Phelipe Teruel, impresor, de que se le nombre para lo que ocurra a este Ayuntamiento, sin perjuizio del que anteriormente está ejecutado en Phelipe Díaz Cayuelas; y también la notoria habilidad de aquel, pues por lo mismo está elegido por tal impresor del Illmo. Señor Obispo, y su Cabildo Eclesiástico; además de concurrir en su persona las zircunstanzias que se requieren: Desde luego el Ayuntamiento lo nombra por su impresor, sin que esta elección perjudique a las regalías del expresado Cayuelas; $y$ en virtud del obtenga y goze aquellas exempziones que le correspondan: Y para su derecho y resguardo se le de testimonio de esta resolución que le sirva de título en forma". ${ }^{0}$

\section{En Murcia, por Felipe Teruel, Impresor de la Digni- dad, Episcopal.}

Figura 12. Pie de imprenta. Fuente: D. Manuel Rubin de Celis a todos los fieles de este nuestro Obispado. Al fin, diciembre 1773. (B. Archivo Municipal de Murcia).

Conseguido su propósito, en 1772 Teruel comenzaba a poner su taller al servicio de los munícipes con la impresión de varias reales cédulas ${ }^{51}$, y en 1774 hacía constar por primera vez su cargo de "Impresor de la Ciudad", precisamente el año en que la oficina del Plano de San Francisco cerraba sus puertas (García Cuadrado, 2011, p. 315-316) ${ }^{52}$. El dinamismo del impresor y su buen hacer acabarían al servicio de las elites rectoras de la ciudad como siempre había deseado. La cantidad no pequeña de documentos oficiales que da a las prensas durante los últimos diez años de su vida 
está todavía por computar. Basta, sin embargo, hacer una pequeña cata en los Cartularios Reales para comprobar el trabajo realizado para el Ayuntamiento por su impresor ${ }^{53}$.

En poco más de diez años Felipe Teruel Martínez había conseguido acaparar en su persona hasta siete títulos, un número sin precedentes entre los tipógrafos murcianos: Impresor del Santo Oficio de la Inquisición, Impresor del Ilmo. Cabildo de la Santa Iglesia de Cartagena, Impressor de las Reales Fábricas de la Polvora, Impresor del Departamento de Marina de Cartagena, Impresor del Ilmo. Señor Obispo de Orihuela, Impresor de la Dignidad Episcopal (Figura 12) e Impresor de la Ciudad. Una vez desaparecido Díaz Cayuelas, Teruel quedaba al frente de la imprenta murciana, un sector sin competencia y en el que acababa de aterrizar Francisco Benedicto Oliver, el librero de la calle Platería. Ambos profesionales serían durante una década los únicos impresores en todo el Reino ${ }^{54}$.

\section{SEXTA NOTICIA: UNA DÉCADA ASCENDENTE}

Antes de centrarnos en los documentos que avalan el temprano dinamismo del impresor, debemos señalar que en 1761 había comenzado una fructífera y prolongada relación comercial con el mercader de libros José Santiago Gómez. El librero Gómez, natural de Tudela (Navarra), era un joven editor de 31 años con negocio abierto en una céntrica calle de la ciudad ${ }^{55}$. Ignoramos la época de la llegada del mercader a Murcia, pero en julio de 1758 arrendaba dos casas unidas al duque de Veragua en la Trapería ${ }^{56}$, y en 1761 sacaba al mercado un impreso estampado en el taller de Teruel cuya venta estaba siempre garantizada. Se trataba de Los quatro libros de la imitacion de Christo de Tomás Kempis en la conocida traducción del jesuita Eusebio Nieremberg, una bonita impresión en $12^{\circ}$, con portada a dos tintas y con grabados calcográficos sin firma; de este impreso conocemos dos ediciones con el mismo pie de imprenta.

En 1762 ambos asociados ponían en circulación otro texto de carácter devocional, Pensamientos christianos para todos los dias del mes del también jesuita Dominique Bouhours. Para entonces, la oficina del impresor se había trasladado de la calle del Pilar a la cercana calle Lencería, un traslado que sería definitivo. A finales de 1764 Teruel afianzaba la nueva ubicación topográfica de su negocio arrendando durante 4 años a la priora del convento de Santa Ana una casa de morada en la misma calle, quizás ante la necesaria ampliación de la oficina que ya funcionaba a pleno rendimiento ${ }^{57}$.

Unos meses antes, en marzo de 1764, los Teruel habían acudido al notario con objeto de otorgarse mutuamente poderes para testar ${ }^{58}$. Esta escritura viene a confirmar que los negocios del matrimonio iban viento en popa. Solo quien tiene bienes y se embarca en proyectos de cierta envergadura se preocupa por organizar el futuro ante la fragilidad de la vida humana. La lectura del documento proporciona algún pequeño dato de índole sociológica interesante. Además de confirmar la procedencia aragonesa de Felipe y la murciana de su esposa -asunto que ya conocíamos por la partida matrimonial- y de su pertenencia a la feligresía de la parroquia de San Pedro, declaran no tener hijos. Por esta razón, en el caso de fallecer ambos esposos, quedaría como "única y unibersal heredera de todos los [bienes] que así quedasen, María Ignacia Vicente, nuestra sobrina, de estado doncella, para que los aia y lleve libremente”. Después de casi veinte años de matrimonio y una vez perdida toda esperanza de tener descendencia, quién mejor para heredar que la sobrina carnal del impresor, una verdadera hija para ellos. En 1756, según las respuestas dadas al Catastro de Ensenada, María Ignacia Vicente Teruel convivía ya con sus tíos quienes debieron de acogerla desde su venida a Murcia procedente del pueblo turolense de Monteagudo. En aquella localidad había nacido también su hermano Juan Vicente quien no tardaría en arribar a Murcia para trabajar a las órdenes de su tío en la imprenta ${ }^{59}$. Curiosamente, entre los testigos de este primer testamento de los Teruel-Ramírez se encontraba José Fandos, el impresor en otro tiempo autónomo, que habría pasado a ganarse la vida como oficial de imprenta, probablemente como empleado en la propia oficina de la calle Lencería.

Hemos anotado más arriba que el alquiler de la casa a la monjas podría estar relacionado con una ampliación del negocio impresor, un hecho que parece confirmarse con un nuevo documento acerca de la adquisición de ciertos aparejos tipográficos a finales de noviembre de 1764. No se trataba de materiales de nueva factura sino de una parte del defenestrado taller de Nicolás Villargordo. Este impresor había dado poderes al oficial de imprenta José Morenete para que tratase la venta de su imprenta murciana al haber retornado a Salamanca. Según la documentación localizada, una parte de la imprenta fue adquirida por 3.500 reales por el calígrafo y grabador alicantino Pedro Paredes ${ }^{60}$; la otra parte, mucho más menguada, fue vendida "al contado a Phelipe Teruel, vezino de esta referida Ciudad para sí”. Más adelante, el texto especifica que se trataba de "un pedazo de imprenta que se compone de diferentes piezas y con todos sus pertrechos corrientes propia de dicho Nicolás Villalgordo su principal, en prezio de nobecientos veinte y un reales de vellón y diez y siete maravedís vellón en que se ha valuado”,61. 
Dado el escaso importe de la mercancía adquirida, podía tratarse de una parte poco significativa de la antigua imprenta de Villargordo, pero a ella se sumaría en ese mismo año la adquisición de otros elementos decorativos que hemos visto estampados por primera vez en la Construccion del Arte de Antonio Nebrija: methodo facil y breve para aprehender la lengua latina, manual preparado por el maestro de gramática fray Lucas Espinosa. El impreso, destinado a la enseñanza de la lengua latina, fue costeado por el mercader José Santiago Gómez e impreso por Teruel en 1764. Curiosamente, estos elementos decorativos pasarían a formar parte de la imprenta de Francisco Benedicto en los años 70.

Por otro lado, ese mismo año de 1764 un impresor desconocido estampaba la Devocion especialisima y aceptable á el Principe Supremo de la Gloria el Señor San Miguel, el primer impreso cartagenero conservado que fue tirado en la Imprenta Real de Marina. Aunque carente de data tipográfica se indica en su portada que la obrita se ofrece a los devotos del Arcángel por "D. Francisco Rodríguez, Presbítero el menor Capellan de su Santa Casa, en la Ciudad de Cartagena, año de 1764” (Puig, p. 43) ${ }^{62}$. Pues bien, si tenemos en cuenta que Teruel detentaba el título de "Impresor del Departamento de Marina de Cartagena” cabe la posibilidad de que fuera el desconocido artífice del piadoso impreso, un trabajo realizado no en la oficina de la Lencería sino en la propia ciudad Departamental donde bien pudo montar un pequeño taller; allí utilizaría ciertos elementos decorativos que más tarde pasarían también al impresor Benedicto.

La compra de nuevos materiales tipográficos con destino a la ampliación del negocio en Murcia o a surtir la Imprenta de Marina en Cartagena, una hipótesis que no podemos descartar, así como el abandono paulatino de anticuadas xilografías son signos de la marcha ascendente del impresor. Dos años más tarde (1766) lo vemos usar dos nuevos alfabetos floridos que serán ya característicos de sus trabajos (Figura 13); los rasgos estéticos y formales de ambos juegos los acercan a los que se venían empleando en las prensas pamplonesas de Miguel Antonio Domech, antes Herederos de Martínez, al igual que un bonito remate xilográfico (Figura 14) (Itúrbide Díaz, p. 498). No sería de extrañar que en la compra de nuevos materiales decorativos "más a la moda" pudiera haber intervenido, dadas sus fuertes relaciones con el impresor, el mercader José Santiago Gómez, quien debía conocer y mantener contactos con otros impresores, particularmente con los de su tierra natal.
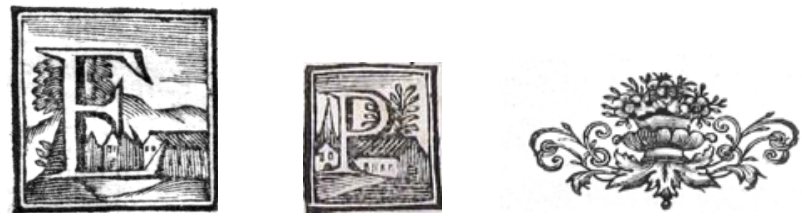

Figura 13. Iniciales y viñeta xilográfica. Fuentes: Directorio moral del R. P. Fr. Francisco Echarri. Murcia: Teruel, 1769 (B. Archivo Municipal de Murcia); Ars vere Philosophandi. Murcia: Teruel, s.a. (B. Franciscana de la Prov. de Cartagena).
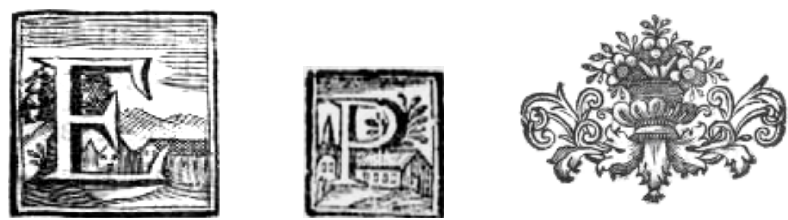

Figura 14. Iniciales y viñeta xilográfica. Fuentes: Ordenanzas de gobierno: método de distribuir propios, y arbitrios de (...) ciudad de San Sebastián. Pamplona, Domech, 1760; Breve modo de aprender gramática, en dialogo. Pamplona, Herederos de Martínez, 1768. (B. Valenciana Patrimonio Bibliográfico).

\section{8. ÚLTIMA NOTICIA: LA TEMPRANA DESAPARICIÓN DE UN GRAN TIPÓGRAFO}

La delicadísima salud del impresor desde 1779, con tan solo 57 años, llevaría al matrimonio al registro notarial. Existen dos testamentos consecutivos ${ }^{63}$; el último, con el postrero testimonio de su rúbrica, está fechado el 5 de octubre de 1780. No se ha conservado su partida de defunción, pero esta debió producirse prontamente pues en noviembre la viuda presentaba memorial al Ayuntamiento. Para Antonia Ramírez era perentorio afianzar en su persona lo conseguido por su esposo. La respuesta del Concejo de 25 de aquel mes dice lo siguiente ${ }^{64}$ : 


\begin{abstract}
Viose Memorial de Antonia Ramírez, viuda de Phelipe Teruel, vezina de esta Ciudad, en que dize que su difunto marido merezió a la justificazión de este Ayuntamiento le nombrase por su impresor en el año pasado de mill setezientos setenta y uno, desde cuyo tiempo le ha estado sirviendo como es notorio; y habiéndose quedado la suplicante por heredera y en su cabeza toda la imprenta, la que govierna y manexa su sobrino Juan Vicente Teruel, quien ayudaba a su tío por estar hábil en esta facultad, que ha manexado en su compañía más de diez y seis años. En estos términos espera de la grandeza de esta Ciudad que atendiendo al arto mérito que hizo su difunto marido, al costo que le tubo las clases de letras que compró para perfeczionar dicha imprenta, y a haber quedado la referida con bastantes estrechezes, se digne por un efecto de su bondad y liveralidad nombrarla con el mismo encargo que confirió a aquel; con lo demás que contiene; de el qual se hizo relación, y el Ayuntamiento en si intelixencia, contemplando la zerteza de lo expuesto por la zitada Antonia Ramírez, y que es mui debido atenderla, desde luego = Acuerda no se haga novedad en el nombramiento de impresor que executó en dicho Phelipe Teruel su marido, y lo confiere de nuevo a esta interesada mediante a haber quedado a su cargo la imprenta corriente, bien surtida de letras, y con suxeto hábil que la manexe. Y que se le de a la referida testimonio de esta resoluzión para su resguardo.
\end{abstract}

Mucho había cambiado la situación del matrimonio al finalizar la década de los setenta. Tal es así, que la redacción de los testamentos antes citados tendrán muy en cuenta a quien desde hacía más de 16 años trabajaba en la imprenta. Se trataba de Juan Vicente Teruel, el maestro impresor que permitiría a la Viuda de Teruel seguir detentando una posición relevante entre sus colegas. Felipe había levantado y consolidado la mejor oficina tipográfica y Antonia Ramírez incrementará su producción siguiendo los mismos esquemas trazados por el fundador con la ayuda inestimable de su sobrino político y heredero junto a su hermana del patrimonio de los Teruel.

Durante el último año de vida de Felipe la producción de la oficina de la Lencería se encontraba ya muy diversificada en cuanto a la clientela y a la naturaleza de los impresos que salían de sus prensas. Las diócesis de Cartagena y de Orihuela eran sus clientes; los centros docentes como el murciano Seminario de San Fulgencio y el de San Miguel en Orihuela con las académicas tesis latinas de sus estudiantes constituían otra estimada fuente de ingresos que su viuda lograría mantener casi en exclusiva; las cartillas escolares redactadas por el conocido calígrafo Pedro de Paredes, los certámenes literarios de las escuelas públicas alicantinas, los textos científicos e históricos, los variados documentos oficiales y los sermones de los afamados oradores verían la luz poco antes de que Antonia Ramírez tomara las riendas del más próspero negocio tipográfico de la segunda mitad de la Murcia dieciochesca.

\title{
9. PARA CONCLUIR
}

La relación de los nuevos datos que hemos ido desgranando en estas páginas aporta una visión hasta ahora desconocida de algunos nombres de la tipografía murciana y, particularmente, del fundador de la prestigiosa imprenta Teruel. Son varias las cuestiones que merecen ser destacadas.

En primer lugar, la procedencia aragonesa de no pocos nombres entre los libreros que trabajaron en Murcia durante el siglo XVIII. El propio Felipe Teruel ejercerá como vendedor de impresos asociado al también aragonés Antonio Roncales. A pesar de su condición de oficial de imprenta, Teruel formaría parte del colectivo de libreros desde su llegada a la ciudad.

No podemos descartar que Orihuela constituyese para el joven librero el punto de arranque del oficio de impresor. Su clara relación con el tipógrafo oriolano Alagarda, en cuya oficina bien pudo haber trabajado y perfeccionado sus habilidades tipográficas, harían de Teruel un buen profesional antes de abrir taller propio hacia 1758.

La existencia de buenos contactos y clientes de prestigio en la capital de la Vega Baja y en la propia ciudad de Murcia permiten explicar la apertura de la oficina de la calle del Pilar en una época tan crítica para los tipógrafos murcianos. La atonía característica del sector en el Reino debido en buena medida al desinterés de las elites y, por tanto, de las instituciones civiles y religiosas a quienes encarnaban, no impediría al aragonés abrirse camino con una pericia poco común. También la solicitud de un privilegio de impresión utilizando como intermediario a un conocido fundidor de letras de la Corte, evidencia la existencia de contactos nada despreciables fuera del contexto murciano, algo imprescindible para poder mantener sus prensas en activo.

Por otra parte, el deseo de reunir en su persona la totalidad de los nombramientos que habían ostentado con anterioridad otros impresores, y que él conseguirá obtener en algunos casos de manera simultánea -Impresor del Santo Oficio e Impresor de la Ciudad al mismo tiempo que Díaz Cayuelas-, es muestra de un plan bien diseñado desde el inicio de su actividad profesional y de la importancia dada por Teruel al establecimiento de las siempre útiles 
relaciones con las elites de poder. Esta visión del negocio le llevaría a padecer una auténtica “titulitis” incorporando a su palmarés nombramientos hasta entonces desconocidos entre los tipógrafos del Reino -“Impresor de las Reales Fábricas”, e "Impresor del Departamento de Marina de Cartagena”-, al que sumaba el siempre apreciado de "Impresor del Ilmo. Señor Obispo de Orihuela”.

Con el paso del tiempo y la consolidación de su establecimiento, la estética impresora irá evolucionando incorporando otros adornos xilográficos para engalanar sus impresos. La densidad del ornato irá disminuyendo conforme se produzca un abandono del trasnochado barroquismo y una evolución hacia una estética más moderna inspirada, sin lugar a dudas, en los productos editoriales procedentes de fuera del Reino. Teruel incorporará nuevas viñetas y letras floridas que nada tendrán que ver con el “ajuar” de su primera época que, sin embargo, evocará esporádicamente con la reutilización de antiguos adornos todavía en buen estado. En este punto conviene señalar que en los años 70 se hizo labrar una marca o escudo de inspiración barroca, un elemento poco utilizado en la tipografía murciana y que el propio impresor estampará excepcionalmente en sus portadas (García Cuadrado y Herrero Pascual, p. 124).

\section{NOTAS}

${ }^{1}$ A.H.P. Murcia. Prot. 2639, ante José Cano de Santayana, 1746, f.141, “Antonio Roncales, mercader de libros, y Felipe Teruel, ympresor, vecinos desta ciudad, escriptura de convenio".

${ }^{2}$ FamilySearch, Murcia, San Pedro, Matrimonios, 1713-1766, f. 110 v.

3 A.M. Murcia. Legajo, 1062, según el vecindario de San Pedro de 1734 era impresor, estaba casado, tenía 6 hijos y contaba con 40 años. Parece que en los años 30 Vicen Pérez mantenía especiales relaciones de confianza con el maestro tipógrafo José Díaz Cayuelas; en julio de 1738 lo vemos firmar como testigo en compañía del librero Gregorio Gómez en el arriendo que Díaz Cayuelas hacía de su casa de la calle Corredera en la parroquia de San Juan. En agosto, Vicen Pérez vuelve a figurar como testigo en el poder notarial que José Díaz, a punto de morir, otorgaba a un pariente para que practicara su testamento. A.H.P. Murcia. Prot. 3825, ante José Ramos, f. 516 y $564-565$ v. Gerónimo Vicen murió en febrero de 1740 y "no hizo testamento por ser pobre”. FamilySearch, Murcia, San Pedro, Defunciones, 1619-1743, f. 224 r.

${ }^{4}$ A.M. Murcia. Legajo 2499. Según los libros parroquiales, el matrimonio había engendrado dos varones, Juan Antonio, nacido en febrero de 1740 y Eugenio Mariano en septiembre de 1742; ambos infantes morirían muy pronto. FamilySearch, Murcia, San Pedro, Bautismos, 1731-1758, f. 100 r. y $134 \mathrm{r}$.

${ }^{5}$ FamilySearch, Murcia, San Pedro, Matrimonios, 1713-1766, f. 142 r.

${ }^{6}$ FamilySearch, Murcia, San Pedro, Bautismos, 5 marzo 1749.

7 Además de Roncales y el ya citado Juan Royo Pérez, también era aragonés el librero Juan Polo Burillo, natural de la Hoz de la Vieja (Teruel).

${ }^{8}$ FamilySearch, Murcia, San Pedro, Matrimonios, 1713-1766, f. 138 v. Antonia Ramírez García era algo menor que Felipe Teruel pues había nacido en marzo de 1725. FamilySearch, Murcia, San Pedro, Bautismos, 1706-1730, f. 207 r.

9 Nota 1.

10 A.H.P. Murcia. Prot. 2644, ante Cano de Santayana, año 1750. Testamento de Antonio Roncales f. 317-319 v.

${ }^{11}$ El impago de la citada librería de medicina venía de largo; la compra se había llevado a cabo en abril de 1742, según la tasación realizada por Juan Royo y Juan Polo en 5.000 reales vellón. A.H.P. Murcia. Prot. 3314, ante A. López Mesas, f. 125-132. “Antonio Roncales, vezino de esta Ciudad, venta de una librería contra los hijos menores de D. Alfonso Pérez Mesía y su curador ad bona en su nombre”.

12 A.H.P. Murcia. Prot. 2956, ante Gómez de Albacete, f. 202 y ss.

13 A.H.P. Murcia. Prot. 2644, f. 313-315 v. Testamento de Melchora de los Reyes Alonso, suegra de A. Roncales. Muchos años después, la Gaceta de Madrid (martes 10 de noviembre de 1761) anunciaba que la Segunda parte de las Crónicas de la Provincia de San Pedro de Alcántara de Franciscos Descalzos se venden en (...) Murcia, en casa de Rosa Falcón, calle del Pilar.

14 “... y los vienes que poseemos son todos gananciales, adquiridos con nuestra industria y corporal travajo durante nuestro matrimonio”. A.H.P. Murcia. Prot. 3718, ante Pérez Lázaro, f. 675 v.

${ }^{15}$ A.H.P. Murcia. Prot. 2989, ante Esteban González, 1755, f. 42. "Los Maestros de Libreros de esta Ciudad, poder general a Joseph Fernández de Rueda”, "En la Ciudad de Murcia a catorze días del mes de febrero mill setecientos cinquenta y cinco años, en presencia de mí, el escribano público, y testigos parezieron Juan Royo, Francisco Benedito, Gregorio Gómez, Juan Polo, Francisco de Xea y Felipe Teruel todos vecinos, y maestros de libreros de esta Ciudad...”.

${ }^{16}$ El último oficial mencionado, Juan Marín, trabajaba sin duda en la imprenta de Díaz Cayuela; se trata de Juan Marín Montesinos Penalva, emparentado con la familia del impresor por matrimonio con su hija María.

17 Juan Polo Burillo adeudaba 74 reales por cierta cantidad de resmas, probablemente para la impresión de los almanaques que el librero costeaba y mandaba estampar en la imprenta de Díaz Cayuelas para su venta entre los ciegos de la ciudad y pueblos del Reino.

18 A.M. Murcia. Legajo 1052, t. II. “Autos de buen gobierno”: “Que se pague la impresión (...) diligencias antecedentes, fixar edictos impresos en diferentes partes de esta ciudad, y en las hermitas de la dilatada población de su huerta y campo y su gasto indispensable de solo impresión y papel importa setenta y un real y dos maravedís de vellón y debiendo esto exigirse de lo perteneciente a gastos de Justicia (...) se entregue los quarenta y siete reales a don Diego Callejas, Alguacil Mayor de esta Ciudad, quien los ha suplido; los veinte y quatro reales restantes a Joseph de los Llanos, impresor, por el trabajo en la impresión de ducientos edictos, que son libramiento, y recreos de dichas cantidades se abonarán a dicho Depositario en las cuentas de dichos efectos. Nota: En Murcia, a dicho día [29], mes [julio] y año [1754] se despachó el libramiento y se mandó por el auto antecedente".

19 A.M. Murcia. Acta Capitular de 1754, f. 228

${ }^{20}$ Sobre esta cuestión y en relación al nombramiento de “Impresor de su Majestad”, escriben Burgos y Peña: “Es probable que haya que reducir a dimensiones más modestas (aunque no despreciables) la trascendencia que se le ha presupuesto en el conjunto del origen del trabajo realizado y de 
los beneficios obtenidos por las imprentas, las impresiones institucionales”. Para ambos estudiosos, la verdadera importancia residía sobre todo en el prestigio social y en las relaciones que podían llegar a establecerse con los sectores con mayores posibilidades económicas y culturales.

${ }^{21}$ Poco después del quejoso Memorial, el impresor tendría una buena oportunidad de dar trabajo a sus prensas. En el Acta Capitular de 8 diciembre de 1754 se aprobaba la impresión de la oración de exequias de la reina de Portugal que naturalmente fue encargada a Díaz Cayuelas. Oracion funebre: que a las tiernas augustas memorias, y Reales exequias de la Magestad (...) Doña Maria Ana Josepha de Austria, Reyna Viuda de Portugal, consagró la (...) ciudad de Murcia, en la Santa Iglesia Cathedral de esta ciudad, el dia 28. de Noviembre de 1754 / dixola el R. P. Antonio Joseph Lopez de Ayala, de la Compañia de Jesus (...) danla a publica luz (...) don Francisco Fontes (...). En Murcia: en la imprenta de Phelipe Diaz Cayuelas, en el Plano de S. Francisco, [s.a.].

${ }^{22}$ FamilySearch, Murcia, San Antolín, Matrimonios, 1723-1753, f. 287 v. "En la Ciudad de Murcia a veinte y seis días del mes de febrero de mill setezientos quarenta y nuebe, yo don Juan de Sierra Cavallero, Presbítero, haviendo precedido lo dispuesto por el Santo Concilio de Trento con pase del Provisor y Vicario general de este Obispado, ante Francisco Bueno, Notario ex licencia parrochi, desposé por palabra de presente que hazen verdadero matrimonio a Joseph de los Llanos, viudo de Josepha Burruezo, con Ysabel Martínez, muger que fue de Felix Reinel por matrimonio rato, siendo testigos Phelipe Díaz Caiuelas, Antonio Zafra y Juan Paredes. Y para que conste lo firmé. (...) D. Juan Sierra Cavallero [rúbrica]”. FamilySearch, Murcia, San Pedro, Matrimonios, 1713-1766, f. 192 v. "En la Ciudad de Murcia a veinte y seis días del mes de enero de mill setezientos cinquenta y cinco, constándome estar casados Joseph Llanos y Ysabel Martínez en la Iglesia parroquial del Señor san Antolín, en el día veinte y seis de febrero de el año pasado de mill setezientos quarenta y nuebe; y ser actualmente feligreses de esta parroquia, yo don Patrizio López, Cura theniente de esta les velé y dí las bendiciones nupciales según el Ritual Romano, Y para que conste lo firmé. D. Patrizio López [rúbrica]”.

${ }^{23}$ Oracion funebre encomiastica que en las honras á la gloriosa memoria de (...) Don Phelipe V. celebradas en la Parroquial de Señora Santa Maria del Rosario de la Villa de Alcazar de San Juan, (...) dixo Fr. Francisco Costa Navano (...) Guardian del Convento de N. Seraphico Padre San Francisco (Observantes); sale a luz a expensas del señor Don Sebastian de Rioxa. En Murcia: en la imprenta de Joseph Fandos, [s.a.]; Patrocinio del glorioso patriarca San Joaquin (...) mejorado en esta tercera impression por su autor Fr. Juan Bautista Joaquin de Murcia (...) del Orden de Menores Capuchinos. En Murcia: por Joseph Fandos, 1748; Rara, y maravillosa ave del Oriente, Maria Santissima de las Maravillas: que vino de Italia a España à enriquecer à los españoles (...) su autor Fr. Francisco Moreno de la Regular Observancia de N. P. San Francisco. En Murcia: en la imprenta de Joseph Fandos Ximeno, enfrente de San Lorenzo.

${ }^{24}$ La oficina de los Mesnier, tradicionalmente al servicio del Obispo, estuvo en la calle Platería hasta la muerte del primer marido de María Mesnier, Juan Martínez, pasando a la calle de Zambrana a partir de 1739; en 1742 lo hacía a la Plazuela de Santa Quiteria hasta su clausura definitiva en 1746, siendo regente Pedro Carreras.

25 A.H.P. Murcia. Prot. 2625, ante Diego Antonio Callejas, f. 169. "Phelipe Teruel, vezino e impresor de esta ziudad, poder especial a Bernardo Ortiz”.

${ }^{26}$ Annual novena de la sacratissima y serenissima reyna de los cielos Maria Santissima del Populo. En Murcia: por Phelipe Teruel, calle del Pilar: a expensas de Don Juan Thoribio, y Don Juan Asensio 1759; Annual novena de la sacratissima y serenissima reyna de los cielos Maria Santissima del Populo. En Murcia: por Phelipe Teruel, calle del Pilar: a expensas de Don Juan Thoribio, y Don Juan Asensio 1759; Annual novena de la sacratissima y serenissima reyna de los cielos Maria Santissima del Populo. En Murcia: por Phelipe Diaz: a expensas de Don Juan Thoribio y Don Juan Asensio, [s.a.]

27 Missae propriae sanctorum ecclesiae et Dioecesis Oriolen. quae auctoritate apostolica (...) Pauli V. Pont. Max. Celebrantur. Murciae: Apud Philippum Teruel, 1759.

28 A.H.P. Murcia. Prot. 2375, ante J. Mateo Atienza (1794), f. 1024.

29 Preparacion de la missa, y accion de gracias, segun el Missal Romano: mementos, y otras nueve oraciones, à demàs de las del Missal, muy devotas, quatro para antes del sacrificio, y tres para dar gracias, y la oracion de Ego volo celebrare misma. En Murcia: en la imprenta de Phelipe Teruèl, 1760 .

${ }^{30}$ La lealtad testimoniada, por el distinguido numero de Escribanos, y Procuradores de la muy Noble, Leal, y siete veces Coronada Ciudad de Murcia, a (...) Don Carlos Tercero de Borbón, proclamado Monarcha de las Españas. Oracion que à su gloriosa exaltación dixo (...) el M. R. P. Fr. Joseph Antonio Funes (...) del Orden de Predicadores (...); y dado a luz a expensas del mismo noble Cuerpo. En Murcia: en la imprenta de Phelipe Teruel, vive en la calle del Pilar, 1760.

31 Instrucciones asceticas a Theophilia para el conocimiento practico de Dios que coloca con sumo respeto a la real sombra de las Serenissimas Señoras Infantas de España el M. Fr. Diego Tello Laso de la Vega (...) de la Real Orden de Ntra. Señora de la Merced. Redempcion de Cautivos (...) y Calificador de la de el Santo Oficio Suprema, y Universal Romana Inquisicion. En Murcia: en la imprenta de Phelipe Teruel, vive en la calle del Pilar, 1760.

32 Breve noticia de la vida, y virtudes de la Madre Sor Juana Jacinta Romera (...) de Capuchinas de la Ciudad de Murcia. Murcia: en la imprenta de Phelipe Teruel, Impresor del Santo Oficio, vive en la calle del Pilar, [s.a.]; El cherubin de el paraiso de la Santa Iglesia: Oracion panegyrica, que en la plausible fiesta, que a el esclarecido doctor San Fulgencio, como a su ilustre Patrono consagró su Colegio- Seminario de la ciudad de Murcia. En Murcia: en la imprenta de Phelipe Teruel, Impressor del Santo Oficio de la Inquisicion, vive en la calle del Pilar, 1761.

${ }^{33}$ Aparato para la idea grande de la mediacion, valimiento, y empeño de los Santos para con su Magestad Divina: postila, que en la Santa Iglesia de Cartagena (...) en la Oposición à una Magistral de Pulpito (...) en el dia 11 de Julio de 1762 dixo el Doct. Don Marcelo Miravete de Masseres. En Murcia: en la Imprenta de Phelipe Teruel, Impressor del Santo Oficio de la Inquisicion y del Ilmo. Cabildo de dicha Santa Iglesia, vive en la Lencería, [s.a.].

${ }^{34}$ Villancicos que se han de cantar en la Iglesia Parroq. de Caravaca, en los Maytines del Nacimiento de Nuestro Señor Jesu-Christo, este Año de 1764 puestos en musica por D. Joseph Tornel Torres. En Murcia: por Phelipe Teruel, Impressor de las Reales Fabricas de la Polvora, vive en la Lenceria,[s.a.].

35 José Vicente Alagarda y Eisarch, impresor y grabador oriolano había trabajado en Valencia hasta la apertura de oficina propia en Orihuela en los años 50, antes de que Teruel abriese la suya en Murcia.

${ }^{36}$ La falta de datos de impresión no impide reconocer la procedencia de estos impresos mediante las letras iniciales utilizadas al inicio de los edictos, informes, autos, etc., un tema de gran interés a la hora de elaborar el repertorio tipobibliográfico de este impresor.

37 Así se anota en el pie de imprenta del Inventario reglado para armamento y desarmo del Javeque del Rey. Impreso en Murcia: en la oficina de Felipe Teruel, impresor de Departamento de Marina de Cartagena, [s.a.].

38 Desde 1747 Felipe Díaz Cayuelas era no solo Impresor de la Ciudad y del Santo Oficio, sino también Impresor del Obispo de Cartagena; este último título fue obtenido tras la desaparición de la imprenta Mesnier quienes habían detentado el nombramiento durante décadas como libreros e impresores de los obispos murcianos. El primer impreso que conocemos donde Cayuelas exhibe todos sus nombramientos de manera conjunta es: 
De sacrae eloquentiae dotibus oratiuncula prolusoria: quam die 25 junij 1747 ut praevium apparatum propugnandas à se, suisque commilitonibus rhetoricas theses, in (...) templo civitalis Onolensis dixit D. Josephus Joachimus de Ottondo. Murciae: Apud Philippum Diaz Cayuelas, Typ. Civit. S. Officii Inquisitionis, \& Illmi. \& Rmi. D. D. Joannis Matheo, Episcop. Carthag.

39 A. M. Murcia. Acta Cap. de 23 de agosto de 1738, f. 215 v.: "Phelipe Díaz, pide se le nombre por impresor. Viose memorial de Phelipe Díaz Cayuela, diziendo que Joseph Díaz Cayuela, su tío, impresor de esta Ziudad, ha fallecido, y como su heredero ha recaído en su cabeza dicha imprenta, y mediante que ha de continuar en este empleo: Suplica a la Ziudad se sirva de nombrarlo por su impresor, como lo fue dicho su tío con el goze de las exzepciones, y preeminencias pertenecientes a dicha ocupación: Haviéndolo ôydo acordó que el Sr. D. Pedro de Torres, regidor, se informe de la havilidad de esta parte y de lo que resultare traiga razón”. Acta Cap. de 13 sep. de 1738, f. 232 r.: "Impresor. La Ziudad nombra por su Impresor â Phelipe Díaz en lugar y por muerte de Joseph Díaz Cayuela, su tío, para que como tal menestral goze de las exzepciones que le corresponden como â los demás menestrales, todo ello en vista del informe hecho por el Sr. D. Pedro de Torres, regidor, â quien se cometió en cavildo de veinte y tres de Agosto el examen del Memorial dado por esta parte â quien se le despache título en forma”.

${ }^{40}$ A. M. Murcia. Acta Cap. de 20 de nov. De 1738, f. 261 "Impresor. Al memorial de Juan Mesnier, suplicando se le nombre por impresor de la Ziudad. Oído acordó no hacer lugar”.

${ }^{41}$ A. M. Murcia. Acta Cap. de 23 de agosto de 1738, f. 216 r. "Vida del Beato Fr. Martín de Armenta”.

42 A. M. Murcia. Acta Cap. de 9 de septiembre de 1738, f. 227 v. "Impresión de la Vida del R. P. Fr. Martín de Harmenta”.

43 A. M. Murcia. Acta Cap. de 7 de abril de 1739, f. 94 r.

44 Ave del Paraiso, el venerable Fr Martin Perez de Armenta, Religioso lego de N. P. S. Francisco en la Santa Provincia de Cartagena. Compendio de la vida, y muerte de este extatico varon (...). Su autor el R. Fr. Joseph Thomas Blanco, Lector de Theologia e hijo de la misma Santa Provincia. En Valencia: por Antonio Balle, junto à San Martin, 1739.

45 A. M. Murcia. Acta Cap. de 1 de nov. de 1747, f. 276 v. "Se imprima el sermón de la canonización de los religiosos capuchinos”. Sermon: (...) de San Fidel de Sigmaringa y S. Joseph de Leonisa, capuchinos, en que hizo la fiesta a sus magnificas expensas la (...) ciudad de Murcia predico (...) Joachin Navarro, de la Compañia de Jesus (...); lo saca a luz la ciudad. En Murcia: en la imprenta de Nicolàs Villargordo Alcaráz, [s.a.].

46 Sermon panegyrico, predicado en el primer dia de la solemnissima octava de canonizacion de S. Fidel de Sigmaringa (...) y al martyr (...) S. Joseph de Leonisa capuchinos: en que hizo la fiesta a sus expensas el Ilmo. Cabildo de Cartagena (...) dixole el M. R. P. M. Pedro Thomas Torrubia, de la Compañia de Jesus. En Murcia: por Nicolás Joseph Villargordo Alcaraz. En la calle de la Freneria, 1748.

47 Sermon panegyrico: predicado en el tercero dia de la solemnissima octava de canonizacion de San Fidel de Sygmoringa, (...) y del Martyr San Joseph de Leonisa, capuchinos dixole (...) Don Antonio Garcia Benito (...); y adjunta a el va una obsequiosa relación de las fiestas, que se celebraron en (...) Murcia. En Murcia: en la imprenta de Nicolás Villargordo Alcaráz, [s.a.].

${ }^{48}$ Oracion panegyrica a los dos proceres de la santidad, prodigios de la gracia (...) San Fidel de Sygmaringa, pratomartyr de la Congregacion de Propaganda Fide y San Joseph de Leomissa, insigne apostol de Italia: en su proclamada solemne canonizacion (...) dixola Fr. Joseph Antonio Funes del Orden de Predicadores. En Murcia: por Phelipe Diaz Cayuelas, 1747.

${ }^{49}$ Vida de S. Fidel de Symaringa (...) por Fr. Maximiliano de Vanhgena (...); y aora nuevamente traducida del idioma italiano al español por Fr. Feliz Maria de Parma; dalo a luz un devoto del santo. En Murcia: por Phelipe Diaz Cayuelas, 1747.

${ }^{50}$ A. M. Murcia. Acta Cap. de 19 de nov. de 1771, f. 353. "Nombramiento de impresor sin perjuizio del de Phelipe Cayuelas".

51 A. M. Murcia. Cartularios Reales, sig. 864, 1772. En el cartulario de ese año hemos visto reimpresas por Teruel tres reales cédulas y una instrucción; por su parte, Díaz Cayuela tiene sólo una real cédula y una pragmática sanción. Al año siguiente, el Cartulario (sig. 865) acoge una instrucción y otros dos impresos estampados en las prensas de Teruel y ninguna en las de Díaz Cayuelas.

52 Pragmatica sancion de S. M. en fuerza de ley, por la qual se prescribe el orden con que se ha de proceder contra los que causen bullicios, ó conmociones populares. Año 1774. En Madrid: En la Imprenta de Pedro Marin; y por su original en Murcia, por Felipe Teruel, Impresor de dicha Ciudad.

${ }^{53}$ Los pagos efectuados al impresor por su trabajo son otra muestra de su actividad al servicio del Ayuntamiento. En 1780, el año de su muerte, se le pagaron entre febrero y junio un total de 708 reales por los diversos trabajos de impresión realizados. A.M. Murcia, leg. 4232, Propios y arbitrios, 1780 .

54 A.H.P. Murcia. Prot. 2348, ante J. M. Atienza, 1780, f. 288. Teruel y Benedicto, los únicos impresores de la ciudad y del Reino, dan poder a Inocencio Mateo Pérez, vecino de la villa y Corte para que los ayude y defienda en todos sus pleitos.

55 José Santiago Gómez Moros fue bautizado en Santa María, Tudela (Navarra) el 25 de julio de 1731. Era hijo de Manuel Gómez, de Tudela, y de Francisca de Moros natural de Estella. Número de microfilm de FamilySearch: 1359573.

${ }^{56}$ A.H.P. Murcia. Prot. 2671, ante José Leandro Castilblanque, f. 160-162 v. "El Excmo. Señor Duque de Veragua, arrendamiento contra Joseph Santiago Gómez".

57 A. H. P. Murcia. Prot. 3221, ante Jordán Fernández, f. 61. "Sor Ana María Mesía, Priora del Combento de Señora Santa Ana, arrendamiento contra Phelipe Teruel”. Aunque el contrato con las religiosas se formalizó en febrero de 1765, funcionaba desde el año anterior. El arriendo quedó fijado mediante el pago anual de 600 reales.

58 A.H.P. Murcia. Prot. 3342, ante López Mesas, f. 197-198 v. "Phelipe Teruel y Antonia Ramírez, su lexítima, vezinos de esta Ciudad, poder para testar el uno al otro".

59 Los sobrinos de Felipe Teruel eran hijos de Francisco Vicente, natural de Monteagudo y de Josefa Teruel, natural de Aguilar, poblaciones pertenecientes al Obispado de Teruel. FamilySearch, Murcia, San Pedro, Matrimonios, 1767-1795, f. 48 v.

${ }^{60}$ A.H.P. Murcia. Prot. 3220, ante Joaquín Jordán Fernández, f. 299-300 v. “José Morenete como apoderado de Nicolás Villargordo, escritura de obligación y carta de pago contra D. Pedro Paredes, vezino de la ciudad de Alicante”.

61 A.H.P. Murcia. Prot. 3220, ante Joaquín Jordán Fernández, 1764, f. 434. "Phelipe Teruel, vecino de esta ciudad, venta contra Nicolás Villargordo".

62 En opinión de Puig, la novena a S. Miguel sería una simple prueba que no tuvo continuidad; nada dice, sin embargo, acerca del impresor que pudo llevar a cabo aquel pequeño trabajo tipográfico en el Arsenal de Cartagena. Después de este primer intento, y tras algunos años sin producción alguna, comenzaría la actividad del primer impresor conocido, Pedro Ximénez y López, que desde 1784 a 1791 proporciona los impresos a la tipografía cartagenera.

63 A.H.P. Murcia. Prot. 3718, ante Pérez Lázaro, f. 674-676 v. (dic. 1779) y Prot. 3719, ante López Lázaro, f. 461-463 v. (oct. 1780).

64 A. M. Murcia. Acta Cap. de 25 de nov. de 1780, f. 333 r.- 334 r. "Nombramiento de Impresor para lo que ocurra a la Ciudad”. 


\section{BIBLIOGRAFÍA}

AGUILAR PIÑAL, F. La prensa Española en el siglo XVIII, diarios, revistas y pronósticos. Madrid: C.S.I.C., 1978 (Cuadernos Bibliográficos, 35).

BURGOS, F.J. y PEÑA DÍAZ, M. Imprenta y negocio del libro en la Barcelona del siglo XVIII. La casa Piferrer. Manuscrits: Revista d'història moderna, 1987, nº 6, p. 184-218.

GARCÍA CUADRADO, A. Una imprenta murciana del siglo XVIII: aproximación a su producción bibliográfica (1759-1780). En: R. ESCAVY ZAMORA y otros, (ed.). Amica Verba in honores Prof. Antonio Roldán Pérez. Murcia: Servicio de Publicaciones de la Universidad de Murcia, 2005, t. I, p. 299-315.

GARCÍA CUADRADO, A. Imprenta y grabado en Murcia en el siglo XVIII. Boletín de la ANABAD, 2006, vol. 56, nº 3, p. 207-226.

GARCÍA CUADRADO, A. Algunos datos para la historia del grabado en Murcia. En: El libro como objeto de arte. Actas del II Congreso Nacional sobre Bibliofilia, Encuadernación Artística, Restauración y Patrimonio Bibliográfico. Cádiz, abril de 2004. Cádiz: Ayuntamiento, 2008, p. 165-183.

GARCÍA CUADRADO, A. Los Royo en la Murcia del siglo XVIII: apuntes sobre librería y conflictos entre libreros. Carthaginensia, 2009, vol. 25, nº 48, p. 407-437.

GARCÍA CUADRADO, A. La librería de Juan Polo en Murcia a mediados del siglo XVIII. Investigaciones bibliotecológicas (México), 2009, vol. 23, n 49, p. 14-42.

GARCÍA CUADRADO, A. Cesión del privilegio de impresión de libros doctrinales para el Reino de Murcia. Tejuelo, Revista de ANABAD-MURCIA, 2009, n 9, p. 36-45.

GARCÍA CUADRADO, A. La librería en el siglo XVIII: el murciano Juan Polo Ruiz. Murcia: Universidad de Murcia, Servicio de Publicaciones, 2010.

GARCÍA CUADRADO, A. Nuevos documentos sobre tipografía murciana del siglo XVIII. Revista General de Información y Documentación, 2011, vol. 21, n 1, p. 313-333.

GARCÍA CUADRADO, A. y HERRERO PASCUAL, C. La herencia de papel. Primeros siglos de imprenta en Murcia. Murcia: Ediciones Tres Fronteras, 2008.

GARCÍA SORIANO, J. Anales de la imprenta en Murcia y noticia de sus impresores. Suplemento de la Biblioteca del Murciano, t. II. Madrid: Imprenta de García Enciso, 1941.

ITÚRBIDE DÍAZ, J. El impresor “audaz” y "perjudicial” en Pamplona en el siglo XVIII. Miguel Antonio Domech (ca. 1716-1786). Príncipe de Viana, 2002, nº 226, p. 473-519.

LEMEUNIER, G. (intr.). Murcia 1756 Según las Respuestas Generales del Catastro de Ensenada. Madrid: Ediciones Tabapress, 1993.

MOLL ROQUETAS, J. La Biblioteca Real y los juegos de matrices existentes en Madrid alrededor de 1760. Boletín de la $A N A B A D, 1992$, vol. 42, $\mathrm{n}^{\circ}$ 1, p. 9-23.

PAREDES ALONSO, J. Mercaderes de libros: cuatro siglos de historia de la Hermandad de San Gerónimo. Salamanca; Madrid: Pirámide; F.G.S.R., 1989.

PONZ, A. Viage por España ó Cartas en que se da noticia de las cosas más memorables, t. III. Madrid: Joaquín Ibarra, 1774.

PUIG, A.J. del. El arte tipográfico en Cartagena: (desde sus orígenes hasta 1900). Cartagena, 2004.

REYES, A. de los. Publicaciones periódicas en el siglo XVIII en Murcia: nuevas aportaciones. Murgetana, 1990, $\mathrm{n}^{\circ}$ 81, p. 69-89.

VIÑAO FRAGO, A. Aprender a leer en el Antiguo Régimen: cartillas, silabarios y catones. En: ESCOLANO BENITO, A. (dir.). Historia ilustrada del libro escolar en España. Madrid: Fundación Germán Sánchez Ruipérez, 1997, p. 177-183. 